\title{
FINDEV (FISH FINDER AND VISUAL IMAGING REMOTE UNDERWATER VEHICLE) INOVASI ROBOT BAWAH AIR UNTUK MELAKUKAN PENCITRAAN VISUAL DAN PENJEJAK IKAN
}

\author{
Good Rindo*, Samuel" Saefulloh Misbahudin*, Tomi Ahmad Maulana*, Mohamad Nur Aulia \\ * Universitas Diponegoro \\ Departemen S1 Teknik Perkapalan \\ Jl. Prof. Soedarto, SH, Tembalang, Semarang \\ E-mail: good.rindo@ft.undip.ac.id \\ \# Universitas Diponegoro \\ Departemen S1 Teknik Elektro \\ Jl. Prof. Soedarto, SH, Tembalang, Semarang
}

\begin{abstract}
Abstrak
Indonesia memiliki sumberdaya alam terutama sumberdaya perikanan yang melimpah, namun pada kenyataannya sumberdaya perikanan tersebut masih belum mampu untuk dipetakan sehingga para nelayan masih kesulitan untuk menemukan daerah penangkapan ikan. Penulis membuat prototipe Findev (Fish Finder and Visual Imaging Remote Underwater Vehicle) yaitu sebuah wahana bawah air yang mampu melakukan pencitraan visual dan penjejakan ikan. Findev menerapkan teknologi ROV atau Remotely Operated Vehicle dan prinsip hidrostatis equilibrium. Findev memiliki dimensi panjang total 535,5 mm, lebar total 304,2, dan tinggi $248 \mathrm{~mm}$. Findev menggunakan kerangka yang terbuat dari material nylon yang memiliki tensile strength sebesar $700-850$ $\mathrm{kgf} / \mathrm{cm} 2$. Findev memiliki displacement sebesar 12,1 dengan densitas sebesar 1,599 $\mathrm{g} / \mathrm{cm} 3$. Mampu beroperasi dikedalaman $20 \mathrm{~m}$ dengan tekanan hidrostatis sebesar 200,1 Mpa dan gaya tekan kebawah sebesar 118,58 N. Dengan motor bilge pump berkekuatan $1100 \mathrm{GPH}$ dan daya rata - rata sebesar 56,72 Watt, Findev dapat bertahan selama 1 jam beroperasi di air. Sistem sonarnya didukung oleh sonar ventrior VT-FF001 yang memiliki jarak jangkau 325 kaki
\end{abstract}

Kata kunci: Potensi, ROV, Hidrostatis, Stabilitas, Jangkauan

\begin{abstract}
Indonesia has natural resources, especially abundant fisheries resources, but in reality these fisheries resources are still unable to be mapped so that fishermen still find it difficult to find fishing grounds. The author makes a prototype of Findev (Fish Finder and Visual Imaging Remote Underwater Vehicle) which is an underwater vehicle capable of performing visual imaging and tracking fish. Findev applies ROV technology or Remotely Operated Vehicle and the principle of hydrostatic equilibrium. Findev has dimensions of total length of $535.5 \mathrm{~mm}$, total width of 304.2, and height of $248 \mathrm{~mm}$. Findev uses a framework made of nylon material which has a tensile strength of $700-850 \mathrm{kgf} / \mathrm{cm} 2$. Findev has a displacement of 12.1 with a density of 1,599 $\mathrm{g} / \mathrm{cm} 3$. Capable of operating at a depth of $20 \mathrm{~m}$ with a hydrostatic pressure of $200.1 \mathrm{Mpa}$ and a downward force of $118.58 \mathrm{~N}$. With a 1100 GPH bilge pump motor and an average power of 56.72 Watt, Findev can last for 1 hour operating in water. The sonar system is supported by the VT-FFO01 sonar ventrior which has a range of 325 feet

Keywords: Potential, ROV, Hydrostatic, Stability, Range
\end{abstract}




\section{Introduction}

Indonesia merupakan negara maritim terbesar di dunia. Hampir 70\% luas wilayah Indonesia merupakan perairan. Laut yang luas menyimpan kekayaan yang melimpah baik itu sumberdaya perikanan dan sumberdaya mineral. Laut Indonesia yang berada diantara dan disekitar kepulauan Indonesia merupakan satu kesatuan wilayah nasional Indonesia, disebut sebagai laut Nusantara merupakan aset nasional yang berperan sebagai sumber kekayaan alam, sumber energi, sumber bahan makanan, media lintas laut antar pulau, kawasan perdagangan, dan wilayah pertahanan keamanan(Darsono, 1999)

Namun, sumberdaya laut yang besar masih belum dimanfaatkan semaksimal mungkin. Hal inidikarenakan kurangnya data kelautan yang meliputi pemetaan wilayah laut dan dasar laut. Samosir et al (Samosir et al., 2012) mengungkapkan bahwa kondisi perairan laut pada kedalaman tertentu tidaklah mudah dipahami secara menyeluruh jika hanya mengandalkan kemampuan manusia tanpa didukung fasilitas pendukung lainnya seperti ketersediaan peralatan dan teknologi yang memadai. Banyak faktor penyebab keterbatasan manusia dalam mengumpulkan data kelautan secara langsung.

Salah satu peralatan yang telah dikembangkan untuk mengatasi kendala tersebut adalah Remotely Operated Vehicle (ROV). Remotely Operated Vehicle (ROV) pada dasarnya merupakan sebuah wahana berbentuk robot yang dapat beroperasi di perairan laut. Sistem ROV merupakan kesatuan dari wahana (robot) yang terhubung melalui kabel ke pengontrol yang berada di permukaan (ROV committee of the Marine Technology Society, 2010). ROV termasuk ke dalam UMV atau Unmanned Marine Vehicles. Ada 3 kategori UMV menurut Karl von Ellenrieder (2015) (Ellenrieder, 2015) yaitu:

1. 1U/W Remotely Operated Vehicles (ROVs), yang dapat bergerak menggunakan kendali remote.

2. Autonomous/Unmanned Underwater Vehicles (AUVs/UUVs), yang diprogram untuk dapat bergerak tanpa perintah dari manusia.

3. Unmanned Surface Vehicles (USVs), adalah robot kapal yang dapat bergerak atau dioperasikan secara otomatis tanpa perintah dari manusia.

Pada prinsip Archimedes, setiap benda yang sebagian atau seluruhnya terbenam dalam cairan diangkat oleh gaya yang sama dengan berat cairan yang dipindahkan.jika entah bagaimana suatu benda secara instan dapat mengisi rongga dengan cairan yang identik dengan sekitarnya, tidak ada gerakan yang akan terjadi, berat benda akan sama dengan cairan yang dipindahkan (Molland, 2011). Maka dari itu rasio antara massa ROV dengan volume ruang di dalam ROV haruslah sama atau lebih besar dari fluida di sekitar. Penggunaan sistem ballast seperti pada kapal selam akan diterapkan dalam penelitian ini. Penggunaan ballast diharapkan dapat memperingan berat dari ROV dan daya yang diperlukan untuk menyelam (dive)

Penempatan komponen dan distribusi berat akan sangat mempengaruhi ROV. Berat harus di distribusikan dengan merata agar titik pusat grafitasi (Centre of Gravity) atau CG tepat di tengah apabila di lihat dari sumbu y. Sementara itu penempatan titik apung (Centre oh Buoyancy) atau CB harus tepat di atas titik CG (Molland, 2011). Hal tersebut sangat mempengaruhi righting moment atau moment pembalik saat ROV mengalami rolling (gerakan berputar pada sumbu x).

Tekanan hidrostatis pada ROV akan berubah seiring dengan bertambahnya kedalaman. Semakin dalam ROV mampu menyelam maka tekanan hidrostatis yang di alami semakin tinggi. Hal itu apabila tidak diatasi dengan bahan dan kerangka yang sesuai maka akan terjadi deformasi. Desain ROV juga sangat berpengaruh terhadap gaya hidrodinamis. Hambatan ROV di dalam air berbeda ketika berada di permukaan.

Penelitian tentang ROV sudah banyak didlakukan sebelumnya. Husin dkk (Husin et al., 2014) misalnya telah melakukan penelitian mengenai studi awal perancangan prototype Remotely Operated vehicle (ROV). Namun ROV dari penelitian tersebut tidak memiliki desain yang hidrodinamis, sehingga mengalami hambatan yang cukup besar. Kemudian Septian dkk (Septian, Rahmania and Nugraha, no date) juga melakukan penelitian mengenai Remotely Operated Vehicle (ROV) untuk Eksplorasi Bawah Air di Lingkungan Industri Perkapalan. Namun ROV yang dikembangkan tidak menggunakan sistem ballast, sehingga diperlukan daya motor yang besar agar ROV mampu menyelam.

Dalam penelitian ini, penulis membuat suatu prototipe yang bernama FINDEV (Fish Finder and Visual Imaging Remote Underwater Vehicle). Findev merupakan alat yang menggunakan teknologi ROV yang memiliki kemampuan untuk melakukan penjejakan ikan (Fish Finding) dan pencitraan visual. Yang mebedakan Findev denga ROV yang telah ada 
adalah penggunaan ballast untuk mengurangi daya motor. Selain itu dilengkapi dengan sonar dan kamera.

Adapun tujuan dari penelitian ini adalah untuk merancang bangun ROV yang dapat medeteksi keberadaan ikan.

\section{Metode}

\subsection{Metode Penelitian}

Penelitian dilakukan selama 4 bulan yaitu sejak bulan April sampai Juli 2019. Adapun tempat yang digunakan untuk melakukan penelitian adalah Kota Semarang Jawa Tengah, Waduk Pendidikan Universitas Diponegoro, Kolam Renang Kodam IV Diponegoro, dan Laboratorium Las dan Material S1 Teknik Perkapalan Universitas Diponegoro.

Perancangan alat dibagi menjadi 5 tahapan, yaitu studi literatur, desain dan analisis komputer, pembuatan kerangka dan struktur, perancangan elektrik dan mekanik, serta pengujian. Studi literatur dilakukan untuk mencari studi - studi terdahulu untuk mendapatkan desain pembanding. Alat di desain menggunakan software Autodesk Inventor dan analisis yang dilakukan menggunakan softwere software yang dibutuhkan seperti maxsurf, delfship, dan autodesk inventor.

Dari desain studi literatur dan desain didapatkan data - data mengenai bahan yang akan digunakan untuk membuat alat. Selanjutnya bahan tersebut digunakan dalam tahap pembuatan kerangka dan struktur. Bahan yang digunakan untuk kerangka adalah material nylon, material ini dipakai karena memiliki ketahanan atau daya lelah yang melebihi material lainnya.

Perancangan elektrik dan mekanik meliputi perancangan sistem gerak, sistem sonar, dan kamera. Sistem elektrik dirancang sedemikian rupa agar terhindar dari konsleting listrik. Langkah terakhir adalah melakukan pengujian. Pengujian dilakukan untuk mengetahui stabilitas dan performa Findev di dalam air.

\subsection{Metode Desain dan Analisis}

Desain Findev memperhatikan prinsp hidrostatis, agar alat mampu bergerak seimbang. Adapun analisis yang dilakukan adalah sebagai berikut:

1. Hidrostik equilibrum, yaitu analisis data hidrostis menggunakan software maxsurf untuk mendapatkan grafik hidrostatis. mengetahui tekanan hidrostatis alat pada keadaan yang ditentukan serta gaya gravitasi yang diperlukan agar alat mampu tenggelam.

3. Anilisis stress, digunakan untuk menentukan besarnya stres pada kerangka saat berada pada kedalaman yang ditentukan.

\subsection{Metode Produksi}

Metode produksi Findev terdiri dari 4 tahapan. Yang pertama adalah metode produksi kerangka. Kerangka yang digunakan menggunakan material nylon. Pemotongan nylon menggunakan mesin CNC. Tahap yang kedua adalah pembuatan main tube dan ballast tube, main tube menggunakan pipa PVC berukuran 5", sedangkan ballast tube menggunakan pipa PVC berukuran 3". Tahap terakhir adalah memasang mounting atau tempat motor. Mountung terbuat dari material plastik yang dibuat menggunakan teknik 3D printing. Sedangkan tahap terakhir adalah assembly atau penyatuan. Semua komponen disatukan menggunakan koneksi mur baut yang memiliki ukuran bervariasi.

\subsection{Pengukuran Daya Motor}

Daya motor didapatkan melalui penelitian langsung di Kolam renang Kodam IV Diponegoro. variabel bebas yang diteliti adalah variabel kedalaman, sedangkan variabel terikatnya adalah perubahan daya motor. Penelitian daya motor ini digunakan untuk mengetahui daya tahan Findev berada di air.

\section{Pembahasan}

\subsection{Desain}

Findev didesain dengan memperhatikan peletakan CG (Centre of Grfity) dan CB. (Centre of Buoyncy) sesuai dengan pedoman pada Maritime Engineering Reference Book. (Molland, 2011)

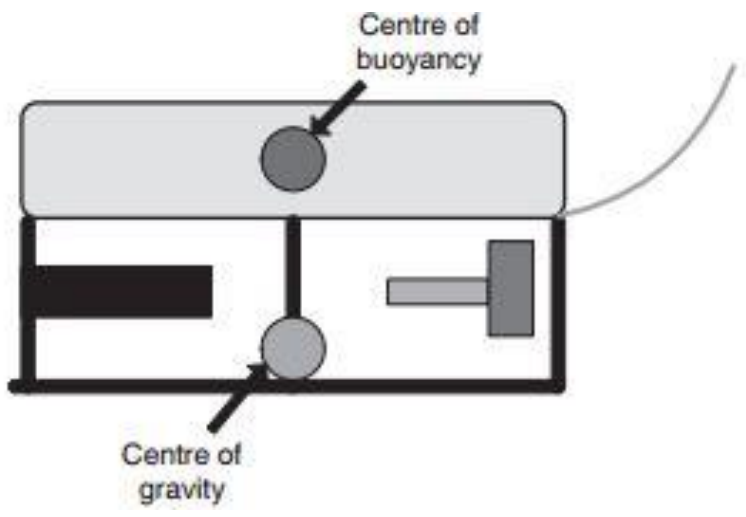

2. Analisis tekanan hidrostais, diguakan unuk 

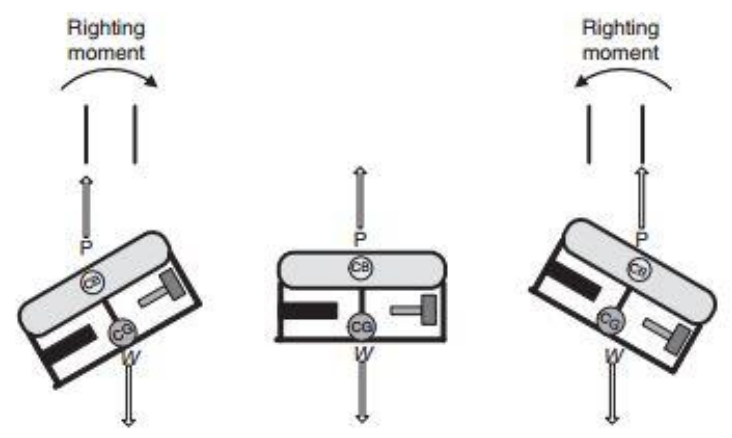

Gambar 1: Peletakan posisi CG dan CB pada wahana bawah air

. Letak CG harus lebih tinggi dari CB agar sudut metasentra yang terbentuk bernilai 00. Sudut metasentra adalah sudut yang dibentuk dari proyeksi titik gaya grafitasi atau $\mathrm{CG}$, dan titik proyeksi gaya apung atau CB. Apabila titik CB berada lebih rendah dari CG maka ROV akan terbalik. Sehingga posisi CB harus di atas titik $\mathrm{CG}$ agar sudut metasentra yang dibentuk sama dengan $0^{0}$.

Findev memiliki ukuran utama (Main Dimension) sebagai berikut :

$\begin{array}{ll}\text { Length of overall (LOA) } & : 535,5 \mathrm{~mm} \\ \text { Breadth of overall (BOA) } & : 304,2 \mathrm{~mm} \\ \text { High }(\mathrm{H}) & : 248 \mathrm{~mm}\end{array}$

Findev tersusun dari 2 sub-unit yaitu submarged unit dan ground control unit. Submarged unit adalah sistem Findev yang menyelam ke kedalaman air dan melakukan pencitraan visual dan penjejakan ikan (fish finding). Untuk desain findev ada pada gambar 2



Gambar 2: Desain dan susunan komponen pada Submarged unit

Findev menggunakan tabung ballast yang berfungsi untuk mengurangi beban yang diakibatkan dari tekanan hidrostatis di kedalaman. Masing - masing tabung ballast memiliki pemberat dengan massa 0.6 $\mathrm{kg}$. Sedangkan keranka atau frame menggunakan material nylon. Material nylon dipilih karena nylon memiliki tensile strength sebesar $700-850 \mathrm{kgf} / \mathrm{cm} 2$, tensile elongation $200-300 \%$, izot impact strength
3,3 - 5,4 kgf/cm2, dan rockwell hardness R119. Untuk desain frame, main tube, ballast tube, dan motor mounting ada pada gambar 3 dibawah ini:


Gambar 3: Desain Frame, Main Tube, Ballast Tube, dan Motor Mounting 


\subsection{Hidrostatik equilibirium}

Data hidrostatik diambil dari grafik hidrostatik yang digunakan untuk mengetahui karakteristik dari bentuk benda yang bergerak di dalam air maupun permukaan air (Rindo, 2015). Penulis menggunakan softwere maxsurf. Untuk grafik hidrostatika ada pada gambar 3 dibawah ini:

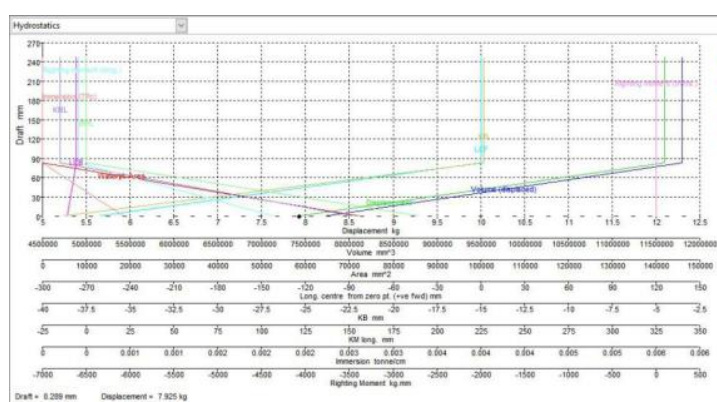

Gambar 3: Grafik Hidrostatik

Grafik hidrostatik menggunakan variabel draft sebagai variabel bebasnya. Draft atau sarat adalah ketinggian benda dari garis dasar benda (baseline) sampai ke permukaan air. Dalam konteks wahana bawah air, perubahan sarat air dimulai ketika benda diletakkan di air, hingga benda seutuhnya berada di bawah permukaan air. Artinya sarat tertinggi yang dapat di capai sama nilainya dengan tinggi Findev yaitu sebesar $248 \mathrm{~mm}$.

Setelah Findev sepenuhnya berada di bawah permukaan air, maka grafik hidrostatisnya bernilai tetap atau konstan. Hal ini ditandai dari grafik yang tegak lurus. Berikut adalah data hidrostatis dari Findev saat berada di bawah permukaan air.

\begin{tabular}{|c|c|c|c|}
\hline & Measurement & Value & Units \\
\hline 1 & Displacement & 12.10 & $\mathrm{~kg}$ \\
\hline 2 & Volume (displaced) & 11809111.7 & $\mathrm{~mm}^{\circ} 3$ \\
\hline 3 & Draft Amidships & 248.0 & $\mathrm{~mm}$ \\
\hline 4 & Immersed depth & 334.2 & $\mathrm{~mm}$ \\
\hline 5 & WL Length & 0.0 & $\mathrm{~mm}$ \\
\hline 6 & Beam max extents o & 0.0 & $\mathrm{~mm}$ \\
\hline 7 & Wetted Area & 478796.3 & $\mathrm{~mm}^{n} 2$ \\
\hline 8 & Max sect. area & 26080.6 & $\mathrm{~mm}^{\mathrm{n}} \mathrm{2}$ \\
\hline 9 & Waterpl. Area & 0.0 & $\mathrm{~mm}^{\circ} 2$ \\
\hline 10 & Prismatic coeff. (Cp) & 0.000 & \\
\hline 11 & Block coeff. (Cb) & 0.000 & \\
\hline 12 & Max sect area coeff & & \\
\hline 13 & Waterpl area coeff. & 0.000 & \\
\hline 14 & LCB length & -277.3 & from $z$ \\
\hline 15 & LCF length & 0.0 & from $z$ \\
\hline 16 & LCB \% & -0.277 & from $z$ \\
\hline 17 & LCF $\%$ & 0.000 & from $z$ \\
\hline 18 & $\mathrm{~KB}$ & -14.9 & $\mathrm{~mm}$ \\
\hline 19 & $K G$ fluid & 0.0 & $\mathrm{~mm}$ \\
\hline 20 & BMt & 0.0 & $\mathrm{~mm}$ \\
\hline 21 & BML & 0.0 & $\mathrm{~mm}$ \\
\hline 22 & GMt corrected & -14.9 & $\mathrm{~mm}$ \\
\hline 23 & GML & -14.9 & $\mathrm{~mm}$ \\
\hline 24 & KMAt & -14.9 & $\mathrm{~mm}$ \\
\hline 25 & $\mathrm{KML}$ & -14.9 & $\mathrm{~mm}$ \\
\hline 26 & Immersion (TPC) & 0.000 & tonne/c \\
\hline 27 & MTC & 0.000 & tonne. \\
\hline 28 & RM at 1 deg $=$ GMt.Di & -3.1 & $\mathrm{~kg} \cdot \mathrm{mm}$ \\
\hline 29 & Length:Beam ratio & 0.000 & \\
\hline 30 & Beam:Draft ratio & 0.000 & \\
\hline 31 & Length: Vor 0.333 rati & 0.000 & \\
\hline
\end{tabular}

Gambar 4: Data Hidrostatik saat Findev Berada di Dalam Air

Dari data hidrostatik didapatkan bahwa dibutuhkan displacement atau berat minimal $12,10 \mathrm{~kg}$ agar alat mampu menyelam. Dan volume air yang dipindahkan ketika Findev menyelam adalah 0,12 m3.
Didapatkan pula data mengenai densitas atau masa jenis Findev, yaitu sebesar $1,599 \mathrm{~g} / \mathrm{cm} 3$ atau 1599 $\mathrm{kg} / \mathrm{m} 3$. Densitas Findev melebihi densitas air tawar ataupun air laut, hal ini dapat diartikan bahwa Findev mampu tenggelam di bawah permukaan air.

\subsection{Analisis Tekanan hidrostatis}

Findev didesain untuk mampu menganalisa potensi perikanan jenis ikan pelagis kecil. Secara spesial densitas ikan pelagis kecil memiliki ukuran densitas ikan tertinggi berada pada kedalaman renang 5-20 meter (Sujatmiko, 2016). Maka dari itu struktur Findev harus mampu menahan tekanan hidrostatis pada kedalaman maksimum 20 meter air laut tanpa mengalami deformasi stress yang besar

Perhitungan hidrostatika yang digunakan untuk menentukan tekanan hidrostatik ditentukan dengan rumus:

$\mathrm{P} \quad: \mathrm{P} 0+\rho \times \mathrm{g} \times \mathrm{h}$.

Ket:

$\mathrm{P} 0=$ Tekananan $[\mathrm{atm}]$

$\rho=$ Berat Jenis air laut $\left[1025 \mathrm{~kg} / \mathrm{m}^{3}\right]$

$\mathrm{g}$ = gaya gravitasi $[9.81 \mathrm{~N} / \mathrm{kg}]$

$\mathrm{h}=$ kedalaman $[\mathrm{m}]$

Dengan P0: 1 atm $(101,325 \mathrm{kPa}), \mathrm{p}: 1025 \mathrm{~kg} / \mathrm{m}^{3}$, g: $9,8 \mathrm{~N} / \mathrm{kg}$, maka didapatkan bahwa tekanan pada kedalaman 20 meter di air laut tersebut adalah $200101,325 \mathrm{kPa}$ atau 200,1 MPa. Dengan berat 12,1 $\mathrm{kg}$, maka didapat gaya tekan ke bawah sebesar 118,58 $\mathrm{N}$.

Namun, karena keterbatasan tempat pengujian, maka pengujian dilakukan di kolam renang Kodam IV Diponegoro yang memiliki kedalaman $5 \mathrm{~m}$ air tawar (densitas sebesar $1000 \mathrm{~kg} / \mathrm{m} 3$ ). pada kedalaman tersebut tekanan hidrostatisnya sebesar 49,10 $\mathrm{MPa}$, sedangkan gaya kebawah bernilai tetap yaitu sebesar $118,58 \mathrm{~N}$.

\subsection{Sistem Kontrol Propulsi}

Rangkaian sistem kontrol Propulsi pada Findev sebagian besar berada pada ground control unit. Ground control unit ini berada di darat, hal ini untuk menghindari konsleting listrik. Hanya lifter dan thruster saja yang berada di bawah air atau di submerged unit. Sistem kontrol propulsi menggunakan accu DC 12 volt 5AH sebagai sumber tegangan. Adapun wiring sistem kontrol propulsi adalah sebagai berikut: 


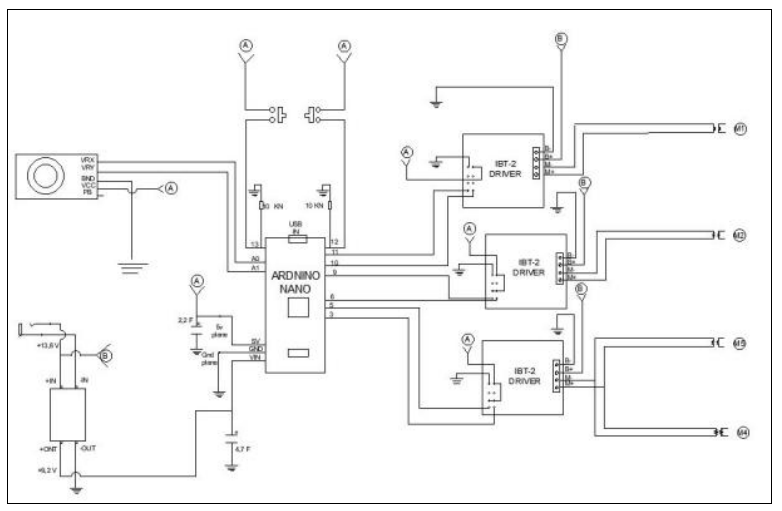

Gambar 5: Wairing Sistem Kontrol Propulsi

\subsection{Sistem Sonar Fish Finding}

Teknologi sonar mirip seperti teknologi Radar (Radio Detection And Ranging), dan ultrasound yang pada dasarnya memanfaaka frekuensi gelombang (Hodges, 2010). Pada dasarnya sebuah sonar atau depth sounder terdiri dari empat bagian, yakni pesawat transmisi/pemancar (transmitter),"transducer", pesawat penerima-pengeras (receiver-amplifier), dan pesawat pengendali dan peraga (control and display).

Untuk dapat memetakan potensi ikan di perairan, Findev di lengkapi dengan sonar Venterior VT-FF001. Sonar ini adalah sonar khusus untuk mendeteksi keberadaan ikan di perairan. Terdiri dari 2 komponen yaitu sonar transducer yang berfungsi untuk memancarkan gelombang dan menerima pantulan dari gelombang tersebut, dan monitor yang berfungsi untuk menampilkan secara visual keberadaan ikan yang ada di perairan sekitar. Sonar mampu menjangkau area seluas 325 kaki.

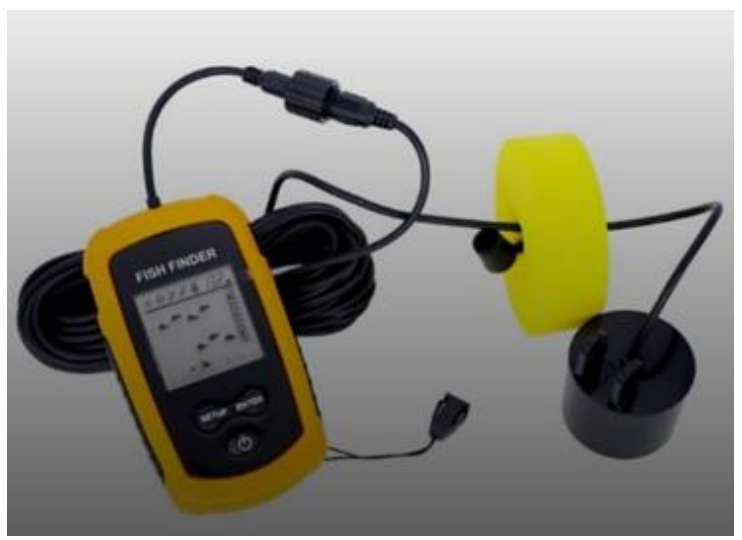

Gambar 6: Sonar Venterior VT-FF001 Fish Finder Portable

\subsection{Olah Gerak (Seakeeping)}

Findev menggunakan pompa bilga (bilge pump) yang dimodifikasi menjadi penggerak (propulsi). modifikasi tersebut adalah penambahan propeller dan pemasangan mounting. Pompa bilga yang digunakan memiliki daya sebesar $1100 \mathrm{GPH}$ (Gallon per Hour).
Sistem propulsi yang ada pada Findev terdiri dari 2 jenis, yaitu Thruster dan Lifter. Thruster berfungsi untuk mengarahkan alat pada sumbu $\mathrm{X}$ dan $\mathrm{Y}$ (gerakan horizontal), sedangkan lifter berfungsi untuk mengarahkan alat pada sumbu Z (gerakan vertikal). Tabel berikut adalah konfigurasi gerak yang ditimbulkan dari kombinasi - kombinasi motor pada Findev.

Tabel 1. Konfigurasi Gerak Findev

\begin{tabular}{cccccc}
\hline \multirow{2}{*}{ No } & \multirow{2}{*}{ Gerakan } & \multicolumn{2}{c}{ Thruster } & \multicolumn{2}{c}{ Lifter } \\
\cline { 3 - 6 } & & Kanan & Kiri & Kanan & Kiri \\
\hline 1 & Surge & Forward & Forward & Off & Off \\
2 & Back & Reverse & Reverse & Off & Off \\
3 & Right Yaw & Off & Forward & Off & Off \\
4 & Left Yaw & Forward & Off & Off & Off \\
5 & Rise & Off & Off & Reverse & Reverse \\
6 & Dive & Off & Off & Forward & Forward \\
\hline
\end{tabular}

Adapun keterangan dari gerakan adalah Surge artinya gerakan ke depan pada sumbu $\mathrm{X}$, Back adalah gerakan ke belakang pada sumbu $X$, Right Yaw adalah gerakan ke kanan pada sumbu Y, Left Yaw adalah gerakan ke kiri pada sumbu Y, Rise adalah gerakan ke atas pada sumbu Z, Dive adalah gerakan ke bawah pada sumbu $\mathrm{Z}$.

\section{7 .Daya Motor Findev}

Berdasarkan hasil percobaan gerakan Findev menurut variabel kedalaman, didapatkan daya rata - rata sebesar 56,72 Watt (Tabel 4.1). Dengan tegangan motor konstan pada nilai 12,2 V. Dari data tersebut maka rata - rata arus yang terpakai adalah 4,65 Ampere.

\begin{tabular}{|c|c|c|c|c|c|c|c|c|}
\hline \multirow{3}{*}{ No } & \multirow{3}{*}{ Gerakan } & \multicolumn{7}{|c|}{ Daya Motor (Watt) } \\
\hline & & \multicolumn{6}{|c|}{ Kedalaman } & \multirow{2}{*}{-Rata - Rata } \\
\hline & & 0 & 1 & 2 & 3 & 4 & 5 & \\
\hline 1 & Surge & 71.8 & 72.1 & 72.5 & 73.2 & 73.6 & 73.7 & 72.82 \\
\hline 2 & Back & 71.5 & 71.7 & 72.3 & 72.7 & 73.1 & 73.3 & 72.43 \\
\hline 3 & Right Yaw & 35.4 & 35.9 & 36.2 & 36.7 & 37 & 37.7 & 36.48 \\
\hline 4 & Left Yaw & 35.2 & 35.9 & 36.3 & 36.5 & 36.9 & 37.5 & 36.38 \\
\hline 5 & Rise & 0 & 72.2 & 72.6 & 73.4 & 73.8 & 74.1 & 61.02 \\
\hline 6 & Dive & 0 & 72.5 & 72.8 & 73.6 & 73.9 & 74.3 & 61.18 \\
\hline \multicolumn{8}{|c|}{ Rata - Rata } & 56.72 \\
\hline
\end{tabular}

Findev menggunakan accu 12 volt dengan kapasitas baterai $5 \mathrm{AH}$. Yang artinya baterai mampu mensuply arus konstan sebesar 5 ampere dalam waktu 1 jam. Jika konsumsi arus Findev saat beroperasi sebesar 4,65 A, maka lama Findev dapat dioperasikan di dalam air adalah 5AH: 4,65 sama dengan 1,07 jam $\approx$ 1 jam.

\section{Kesimpulan}

FINDEV (Fish Finder and Visual Imaging Remote Underwater Vehicle). yang penulis desain memiliki dimensi panjang 535,5 $\mathrm{mm}$, lebar $304,2 \mathrm{~mm}$ dan tinggi $248 \mathrm{~mm}$ terdiri dari 2 sub-unit yaitu submerged unit dan groud control unit. Findev memiliki 
displacement atau berat minimal $12,10 \mathrm{~kg}$ agar alat bisa tenggelam. Findev dirancang untuk mampu memetakan potensi perikanan pada laut dangkal atau zona neritik yang memiliki kedalaman $20 \mathrm{~m}$ dan mampu bertahan di dalam air selama 1,2 jam. Motor pengerak yang digunakan mengunakan pompa bilga yang telah dimodifikasi menjadi penggerak dengan spesifikasi motor 12V 5 Ampere pada putaran 6000 RPM. Propulasi Findev terdiri dari 2 jenis yaitu Thruster dan Lifter, Adapun konfigurasi gerak yang dapat dilakukan oleh findev yaitu Surge, Back, Right Yaw, Left Yaw, Up, dan Dive. Sensor pendeteksi ikan mengunakan sonar Venterior VT-FF001, yang mampu mencakup area seluas 325 kaki. Dengan demikian FINDEV sebagai ROV ini dapat digunakan untuk melakukan pendeteksian Ikan.

\section{Terima kasih}

Penulis mengucapkan terimakasih kepada Departemen S1 Teknik Perkapalan Universitas Diponegoro dan group riset laboratorium teknik perkapalan dan riset marine teknologi (RMT) yang telah menyediakan sarana dan prasana selama kegiatan pelaksanaan penelitian

\section{Daftar Pustaka}

[1] Darsono, P. (1999) 'Pemanfaatan Sumber Daya Laut dan Implikasinya Bagi Masyarakat Nelayan', Oseana. doi: ISSN 0216- 1877.

[2] Ellenrieder, K. Von (2015) 'Applications of Unmanned Marine Vehicles'.

[3] Hodges, R. P. (2010) 'Introduction to Sonar', Underwater Acoustics, 2011, pp. 1-15. doi: 10.1002/9780470665244.ch1.

[4] Husin, Z. et al. (2014) 'Studi Awal Perancangan Prototipe Remotely Operated Vehicle (Rov)', Jurnal Mikrotiga, 1(2), pp. 31-36.

[5] Molland, A. F. (2011) 'The Maritime Engineering Reference Book: A Guide to Ship Design, Construction and Operation', Elsevier, p. 920.

[6] Samosir, T. H. et al. (2012) 'Aplikasi Remotely Operated Vehicle ( ROV) dalam Penelitian Kelautan dan Perikanan di Sekitar Perairan Sulawesi Utara dan Biak Papua', Jurnal Ilmu dan Teknologi Kelautan dan Perikanan Tangkap, 1(1), pp. 22-25.

[7] Septian, R. A., Rahmania, A. and Nugraha, M. I. (no date) 'Remotely Operated Vehicle ( ROV ) untuk Eksplorasi Bawah Air di Lingkungan
Industri Perkapalan'.

[8] Rindo, G., Haryadi, G. D., Zakki, A. F., 2015, "The Study on Stability and Seakeeping Characteristics of the Swimmer Delivery Vehicle in Surfacing Condition", Proceedings of International Conference in Intelligent Unmanned System, Vol. 11. 